\title{
INVESTIGACIÓN
}

Recibido: 26/05/2020 --- Aceptado: 14/12/2020 --- Publicado: 12/03/2021

\section{ACTIVISMO SOCIAL FEMENINO EN LA ESFERA PÚBLICA DIGITAL}

\section{Womens's social activism in the digital public sphere}

(D) 81 $\mathbb{R}^{\circ}$ Marián Alonso-González: Universidad de Sevilla. España malonsog@us.es

\section{RESUMEN}

El presente estudio analiza cómo Internet y las redes sociales han permitido interconectar a mujeres de distintas generaciones para, explotando las oportunidades de instantaneidad, alcance y gratuidad, poner el acento en la lucha contra la violencia de género y las políticas efectivas de igualdad. Desde el enfoque que nos proporciona la revisión hemerográfica analizamos cómo los movimientos \#Yositecreo o la huelga del Día Internacional de las Mujeres de 2018 ponen el acento en el acoso sexual, las agresiones y los abusos a los que son sometidas muchas féminas en el mundo. El ciberactivismo feminista ha abierto una puerta para forjar alianzas, debatir y analizar necesidades, así como para consensuar medidas inclusivas y representativas, pero también ha conseguido, gracias a la presión social, grandes logros como una nueva ley de libertad sexual o un Real decreto-ley que pretende resolver la brecha salarial. No obstante, las mujeres todavía tienen grandes hitos por alcanzar como son la igualdad de oportunidades laborales o un reparto equilibrado en los puestos de dirección, medidas que, gracias a esta acción colaborativa, ocupan cada vez más un lugar destacado dentro de la agenda setting de los gobiernos.

PALABRAS CLAVE: Redes Sociales - Internet - Ciberactivismo - Feminismo Participación - Nuevas tecnologías - Movilización - Cambio social

\section{ABSTRACT}

This paper analyzes how, after years of an apathy participative attitude, women have decided to claim situations of injustice and gender inequality. Social networks have made it possible to interconnect women of different generations, exploiting opportunities for instantaneity, scope and gratuitousness, emphasizing in important

\footnotetext{
1 Marián Alonso-González: Licenciada en Periodismo y Doctora en Comunicación Social por la Universidad de Sevilla, donde ejerce de profesora asociada, ha orientado su investigación a campos relacionados con la Comunicación 2.0, el Periodismo 3.0 y los lenguajes multimedia e interactivos.
} 
aspects as the fight against gender violence and promote gender equality policy. From the perspective provided by the hemerographic reviews, we have analyzed how movements such as \#Yositecreo or the International Women's Day 2018 feminists and put sexual harassment, assaults and abuses into de spotlight. Feminist cyberactivism has opened up to forge alliances, debate and analyze needs, as well as to agree on inclusive and representative measures, but it has also achieved, thanks to social pressure, great achievements such as a new law on sexual freedom or a Royal decreelaw that aims to resolve the gender pay gap. However, women still have great milestones to be achieved such as equal opportunities at work and a balanced distribution in leaderships positions, measures that thanks to this collaborative action increasingly occupy a prominent place in the agenda- setting of governments.

KEY WORDS: Social Networks - Internet - Cyberactivism - Feminism - Mobilization - Participation - Networks - Social changes

\section{ATIVISMO SOCIAL FEMENINO NA ESFERA PÚBLICA DIGITAL}

\section{RESUMO}

O seguinte estudo analisa como a Internet e as redes sociais permitiram conectar mulheres de diferentes gerações para, aproveitando as oportunidades de instantaneidade, alcance e gratuidade, colocar força na luta contra a violência de gênero e as políticas efetivas de como os movimentos \#Yositecreo ou a greve do Día Internacional das Mulheres de 2018 focam no abuso sexual, as agresoes e os abusos aos que sao submetidas muitas mulheres no mundo.O ciberativismo feminista tem criado portas para forjar alianças, debater e analisar necessidades, assim como para negociar medidas inclusivas e representativas, mas também têm-se obtido, devido a pressão social, grandes soluções como a lei de liberdade sexual ou outras para solucionar as diferenças salariais. Não obstante, as mulheres ainda têm grandes desafios por conseguir, como são a igualdade de oportunidades laborais ou uma divisão equilibrada nas posições de direção, medidas que, graças a esta ação colaborativa, ocupam cada vez mais lugares destacados dentro das agendas de discussão dos governos.

\section{PALAVRAS CHAVE}

Redes Sociais - Internet - Ciberativismo - Feminismo - Participação - Novas tecnologías - Mobilização - Mudança social

Cómo citar el artículo:

Alonso-González, M. (2021). Activismo social femenino en la esfera pública digital. Vivat Academia. Revista de Comunicación, 154, 133-156. http://doi.org/10.15178/va.2021.154.e1239 http://www.vivatacademia.net/index.php/vivat/article/view/1239 


\section{INTRODUCCIÓN}

El 23 de agosto de 2007 nacían los hashtags de Twitter. Once años después de su creación, estas etiquetas virtuales se han convertido en un poderoso instrumento para intercambiar opiniones o ideas, muy presente en movimientos sociales, hasta el punto de ser uno de los "signos más influyentes de la era digital" (Diario de Sevilla, 2018). Cada día se comparten 125 millones de hashtags de media en todo el mundo, unas etiquetas que ayudan a los usuarios a ver lo que está pasando y a explorar sobre lo que se está hablando en ese momento, según la propia compañía.

Sin embargo, los hashtags no son exclusividad de Twitter. LinkedIn, Google+, Facebook, Instagram y YouTube son algunas de las redes sociales en las que se usan estos enlaces que sirven para agrupar actualizaciones de un tema específico, lo que les confiere la capacidad de ser una excelente herramienta para visibilizar problemáticas comunes, pues posibilitan el empoderamiento ciudadano y propician un escenario en el que cualquier persona puede consumir toda la información disponible en la red de forma rápida.

Las redes sociales han conseguido que la comunicación de masas sea libre y universal, pues permite a las organizaciones "un contacto casi permanente con sus públicos a unos costes muy reducidos y reforzando el modelo simétrico bidireccional" (Alonso, 2015).

La multiplicidad tecnológica permite que se conozcan mensajes que antes quedaban fuera del circuito comunicacional, favoreciendo la aparición de un nuevo concepto, el ciberactivismo, entendido éste como el conjunto de tecnologías de la información que posibilitan comunicaciones más rápidas en los movimientos y difusiones de información a una gran audiencia para realizar un cambio de la agenda pública y poder visibilizar diversas causas (De Ugarte, 2007).

Esta idea es compartida por Caldevilla (2009), para quien el ciberactivismo se remite a la difusión de información como nudo central de la acción, y por Sierra-Caballero (2018), quien lo considera una revuelta de la imaginación ante el colapso del sistema político tradicional.

Por su parte, Reguillo habla de tecnopolítica, el poder hacer-ver o hacer-creer y de cómo "a través de este sistema multipolar, obligan a los medios convencionales a incorporar temas, asuntos, informaciones que transitan de la red a la calle y viceversa, un logro no menor" (Reguillo, 2017, p.123). Una tesis que comparten Tascón y Quitana (2012) para quiénes estas formas de activismo conllevan la amplificación de mensajes o la reducción de los costes movilización, ya que el espacio público de la red permitiría un intercambio horizontal y relativamente autónomo.

El ciberactivismo se articula en torno al empoderamiento, la cultura colaborativa, la libre distribución y el acceso a la información, así como la autoconvocatoria como 
premisa fundamental de movilización (Burgos, 2017), y el movimiento feminista ha sabido aprovechar estas posibilidades para llamar a la reflexión ciudadana y trabajar en la consecución de una sociedad igualitaria.

Las redes sociales se han convertido en una importante herramienta para comunicar asuntos relacionados con los derechos de la mujer y la igualdad de género, permitiendo que cuestiones locales se conviertan en globales y que cobren protagonismo como agentes activos de los procesos de democratización (Della Porta y Diani, 2006; Giugni, 2004).

El ciberfeminismo tiene sus orígenes en los años noventa en los trabajos de VNS Matrix, un colectivo feminista de artistas cuya práctica activista estuvo centrada en el papel de las mujeres en la tecnología y el arte. Con posterioridad, Sadie Pant abordó en 1997 el "ciberfeminismo como un concepto de argumentación teórica donde los humanos y la teoría de la información encontrarían nuevas formas de construir al sujeto y la identidad humana" (Ramírez, 2019). De hecho, Plant veía en el ciberactivismo "una ventana abierta para acabar con el sistema patriarcal, lo que significa procurar nuevos escenarios para conseguir la igualdad de derechos entre hombres y mujeres" (Gago, 2019, p.12).

Las redes interpersonales no suponen un fenómeno nuevo dentro del ámbito de la comunicación, pero sí lo es que las relaciones entre las personas hayan podido llegar a modificarse hasta el punto de poder hablar de una cultura participativa que transforma la sociedad en la que vivimos (Alonso, 2014). Los movimientos sociales y la sociedad civil han encontrado en las nuevas tecnologías un espacio de debate y de confrontación de ideas, de hecho, "las redes feministas funcionan a nivel local, regional y mundial, con actividades online y offline, difuminando la frontera artificial entre ambos espacios" (Fernández y Rubira, 2012, p.1531).

El aumento de la presencia de las mujeres en Internet ha contribuido a atraer a una “generación de activistas mucho más jóvenes, quienes representan un público objetivo clave en la lucha contra los estereotipos establecidos para alcanzar la igualdad de género" (Escobar, 2016).

Desde esta perspectiva, el ciberespacio se presenta como "una oportunidad para el feminismo para avanzar en la igualdad, el pluralismo y la expresión equilibrada de los discursos de género" (Núñez Puente et al., 2013, p.180), y ello es debido a cuatro características básicas que identifican Feliciano y Mallavibarrena (2013): disponibilidad masiva, capacidad de almacenaje y de originar información, sus usuarios pueden ser productores de contenidos, y la capacidad de discutir y compartir conocimientos entre ellos.

En esta misma línea se manifiestan teóricas como Haraway (1991) y Kember (2003), quienes señalan que la tecnología ofrece nuevas formas de relación social online y, por ende, permite crear nuevos lazos entre las mujeres a fin de evitar que el sistema patriarcal monopolice el escenario virtual. Así, algunos trabajos muestran cómo 
Internet es un espacio de relación donde la visibilización política de las mujeres es posible (Núñez Puente, 2011) y cómo los avances tecnológicos se convierten en parte fundamental del cambio y el progreso (Gajjala y Ju Oh, 2012).

De hecho, con objeto de fortalecer la participación política de las mujeres, la OECD (2018) recomienda tres estrategias efectivas que pasan por garantizar la igualdad de acceso y uso de las nuevas tecnologías, aumentar la capacidad de las mujeres para participar en la toma de decisiones e involucrar a los distintos sectores a fin de reforzar las campañas y ayudar a atraer más atención, tanto a nivel global como local.

Frente a teóricos que señalan el efecto contraproducente que puede tener la comunicación horizontal y la falta de jerarquía en la toma de decisiones (Danitz y Strobel, 1999), Reverter (2009) apunta que Internet es un espacio democrático, libre de prejuicios, en el que las usuarias pueden expresarse sin que se tenga en cuenta ni su género ni su sexualidad.

Pese a que el ciberactivismo abre nuevas vías en la lucha por la igualdad efectiva entre mujeres y hombres, aún existe un importante hándicap a tener en cuenta y es el acceso que ambos géneros tienen a las nuevas tecnologías. En este sentido, y pese a que se reducen las distancias en el uso que las mujeres hacen de las tecnologías en la franja comprendida entre los 16 y los 24 años (INE, 2019), la brecha digital de género continúa, de manera que se mantienen desigualdades en cuanto a los usos y conocimientos de diferentes tipos de TIC, las habilidades para acceder a la información, así como los conocimientos y la formación mediante nuevas tecnologías.

Los valores más altos de la brecha de género en el año 2019 en España corresponden a al grupo de edad de 55 a 64 años, siendo de un 14,2\% puntos, frente al 4,7\% que encontramos entre los 16 y 24 años (INE 2019).

\section{OBJETIVO E HIPÓTESIS}

La hipótesis de partida del presente trabajo es que la presión social ejercida por el activismo femenino en fenómenos como el \#Yositecreo y la huelga general de las mujeres del $8 \mathrm{M}$ ha permitido el empoderamiento de un movimiento que, gracias a la combinación de los universos online y offline, se ha convertido en un medio efectivo para denunciar situaciones de injusticia y ha conducido a grandes logros como una nueva ley de libertad sexual.

Partiendo de esta hipótesis, este artículo se orienta a indagar cómo Internet ha facilitado la difusión de los mensajes del activismo femenino y para ello nos centramos en el contexto de emergencia del \#Yositecreo, como parte de un fenómeno global que arranca con el \#MeToo americano y que culmina con la huelga general del 8M.

Para ello proponemos explorar cómo las nuevas tecnologías de la información brindan al feminismo un nuevo medio para el desarrollo proactivo de sus metas, las 
cuales pasan por erradicar la discriminación, promover la lucha contra los estereotipos de género y sensibilizar sobre cuestiones de derechos y no violencia hacia la mujer.

De forma secundaria intentaremos determinar si la acción feminista en las redes sociales se corresponde con los objetivos de divulgación de convocatorias, organización de acciones, construcción de agenda y autoexpresión que configuran el proceso de "mesomobilización" (Scott y Street, 2000) que propicia una alianza estratégica entre las redes activistas dentro y fuera de Internet para impulsar sus propuestas y consensuar medidas inclusivas y representativas para todas las mujeres que se están viendo reflejadas en cambios legislativos y sociales.

\section{METODOLOGÍA}

Desde el enfoque que nos proporciona la revisión hemerográfica, vamos a analizar cómo los movimientos \#Yositecreo del juicio contra La Manada o la llamada a la paralización de las mujeres del 8 de marzo han encontrado en la red una coyuntura idónea para forjar alianzas, debatir y analizar diferentes necesidades, así como para consensuar medidas inclusivas y representativas para todas las mujeres.

El periodo de estudio elegido es de seis meses, concretamente, de noviembre de 2017 a abril de 2018. La elección de fechas responde a que, desde nuestra perspectiva, consideramos que sin la existencia de un precedente tan importante como es el movimiento mundial \#MeToo, no se hubieran podido dar en las condiciones de fuerza y viralización el fenómeno de \#Yositecreo, una consigna originada en noviembre de 2017 tras la publicación en Facebook de una carta del escritor español Roy Galán en respaldo a la víctima de la agresión de La Manada.

De igual forma, si este caso no hubiera puesto de manifiesto una cultura patriarcal y machista subyacente en la sociedad española en la que se es capaz de contratar a detectives privados para demostrar la "mala reputación" de la víctima, no se podría haber dado la revolución feminista del $8 \mathrm{M}$, y mucho menos las manifestaciones contrarias a la polémica sentencia de La Manada que marcaron la agenda política y social de marzo y abril de 2018.

El método elegido para la aproximación al problema de investigación utiliza técnicas de carácter cualitativo, amén de una revisión de la literatura sobre las relaciones existentes entre feminismo e Internet, para de esta forma realizar una investigación más ajustada a la realidad comunicativa.

Para ello, hemos procedido a realizar una revisión bibliográfica, un "tipo de artículo científico que sin ser original recopila la información más relevante sobre un tema específico" (Guirao et al., 2008, p.3) que nos permita enmarcar el tema dentro de un contexto teórico para, a continuación, realizar una pormenorizada labor de documentación y rastreo de noticias relacionadas con estos movimientos que planteamos a fin de intentar explicar cómo las mujeres han encontrado en la red una coyuntura idónea para forjar alianzas, debatir y movilizarse. 
Desde una perspectiva teórica del intepretativismo hemos realizado un seguimiento de las noticias publicadas en la prensa digital nacional en relación a ambos movimientos para, con posterioridad, proceder a la elaboración de un discurso, en base a los planteamientos de Van Dijk (1980), sustentado en la sintetización de las ideas que reposan en los enunciados y la agrupación de ideas para establecer el sentido del texto en su conjunto.

De forma complementaria, hemos procedido a revisar el papel jugado por las redes sociales y las plataformas de mensajería instantánea en lo que se denomina "repertorio de acción colectiva" que hace referencia a las acciones que realiza la ciudadanía cuando interviene en un conflicto, así como a lo que sabe hacer y a lo que otros esperan que haga (Tilly, 2009) y cómo la incorporación de los hashtags a las estrategias activistas no sólo ha logrado un mayor alcance al movimiento, sino que también "ha potenciado discursos activistas que han cambiado para su adaptación a la esfera pública digital" (Núñez-Puente et al., 2016, p. 66).

Asimismo, hemos querido ver la trascendencia que la huelga de las mujeres del 8M ha tenido en la prensa internacional, y para ello hemos procedido al rastreo de la noticia en las principales cabeceras europeas: el diario francés Le Monde, el británico The Guardian y La Repubblica en Italia, así como la repercusión que ha tenido en la prensa americana (The Washington Post y The New York Times).

\section{RESULTADOS}

En octubre de 2017 asistíamos al nacimiento de un movimiento que se ha hecho viral en las redes sociales y que ayuda a las mujeres que han sufrido abusos a denunciarlos. \#MeToo es el hashtag al que numerosas féminas se han sumado para explicar sus vivencias, sobre todo a raíz de que la actriz Alyssa Milano invitara a las mujeres de todo el mundo a denunciar casos de abuso y acoso mediático en Twitter.

En realidad, el \#MeToo no es nuevo, sino que encuentra sus orígenes una década atrás, cuando la activista Tarana Burke inició un movimiento llamado "Me too Movement" (Movimiento yo también) centrado en mujeres jóvenes que habían sido víctimas de abuso, agresión o explotación sexual. Sin embargo, diez años después, el fenómeno ha cobrado una viralización sin precedentes tras el escándalo de abusos sexuales del productor Harvey Weinstein, acusado en sendos reportajes de los diarios The New York Times $y_{-}$The New Yorker de "comportamientos que van desde el acoso hasta la violación, según denuncias realizadas por más de 40 mujeres" (Llanos, 2017).

La repercusión en las redes sociales ha sido tal que a los tres días el mensaje de Milano contaba con 65.000 comentarios en Facebook y había sido mencionado casi 8 millones de veces. Ello se explica gracias al papel que jugaron las celebridades, primero como víctimas, y luego como defensoras. Tanto es así, que el movimiento \#MeToo traspasó rápidamente las fronteras de Hollywood y mujeres de todo el mundo se 
unieron para visibilizar un fenómeno que no es aislado y que sucede a todos los niveles en la sociedad.

Según Ezy Insights (2018) los medios de todo el mundo publicaron sobre \#MeToo casi 4.000 veces al día a mediados de octubre de 2017, llegando incluso a informar más de esta tendencia que sobre incendios y huracanes. En promedio, se mencionó a \#MeToo 1,1K veces por semana en comparación con las 570 veces que se citaron noticias falsas y las 250 del incendio de la Torre Grenfell en la que fallecieron 71 personas.

A escala global \#MeToo fue tendencia en Twitter en al menos 85 países, incluidos India, Pakistán y Reino Unido. Su repercusión fue tal que, incluso, algunos países llegaron a tener sus propias traducciones, es el caso de Francia donde la periodista Sandra Muller publicó el 13 de octubre su propia experiencia en tan sólo 23 palabras y habló de "son porc" (Su cerdo), un mensaje que fue retuiteado 2.800 veces y que gustó a 2.320 personas (Bekmezian, 2017).

Bajo la etiqueta \#BalanceTonPorc, la red social en Francia se llenó de testimonios de mujeres relatando hechos similares con superiores jerárquicos anónimos en su trabajo o episodios de hostigamiento en las calles, lo cual llegó, incluso, a provocar manifestaciones de solidaridad masculina.

Las repercusiones también se dejaron ver en Italia, \#QuellaVoltaChe, Canadá \#MoiAussi y España bajo la etiqueta \#YoTambién.

Junto al impacto generado en las redes, la campaña \#MeToo cobró especial trascendencia cuando las acusaciones de acoso traspasaron el ciberespacio para incidir directamente en las empresas. En este sentido, el 5 de octubre de 2017 es una fecha clave. Ese día, las periodistas Jodi Kantor y Megan Twohey publicaron en The New York Times un artículo titulado "Harvey Weinstein compró durante décadas el silencio de las mujeres que le acusaban de acoso sexual". Apenas tres días después Wenstein fue despedido de su propia empresa.

Este sería el punto de partida de un movimiento que ha provocado que numerosos actores de Hollywood hayan pasado al ostracismo laboral (Hollywood Reporter, 2017) por casos similares. Es el caso de Kevin Spacey, también acusado por acoso sexual, y que provocó que Netflix cancelara la producción de la exitosa serie House of Cards.

El periodista y locutor Charlie Rose, Louis C.K., Dustin Hoffman, directores como Brett Ratner y James Toback o John Lasseter, que abandonó a finales de 2019 su cargo de jefe creativo en Pixar y Walt Disney Animation Studios, son otros de los nombres propios implicados en casos de abusos y que han provocado cambios en la junta directiva de empresas como Tesla y SpaceX.

\subsection{La Manada y el \#Yositecreo}


Más allá de las denuncias individuales de abusos en el colectivo cinematográfico, el movimiento \#MeToo ha logrado un calado de impacto en la conciencia general de la población, ya que ha puesto de relevancia que el acoso sexual es "transversal a una sociedad machista que cosifica a la mujer y que patrocina la cultura de la violación" (Coronado, 2017).

Sin embargo, pocos son los estudios al respecto, de hecho, las cifras más recientes son de 2014 y proceden de un estudio realizado por la Agencia de Derechos Fundamentales de la Unión Europea que calcula que 120 millones de mujeres de todo el mundo han tenido que soportar en algún momento de su vida besos, abrazos, tocamientos indeseados, comentarios sexualmente insinuantes, mensajes sexualmente explícitos o conductas exhibicionistas (FRA, 2014).

La visibilización de los abusos a través del \#MeToo ha colocado el tema en el centro de la agenda setting de muchos gobiernos, empezando por el norteamericano, donde la lobista californiana Samantha Corbin fundó el grupo We said enough (Hemos dicho basta) que ha denunciado hasta 147 casos de acoso sexual en los pasillos del Capitolio, lo que ha provocado desde la dimisión de un senador y tres asambleístas a la aprobación de leyes que protejan a las denunciantes y la prohibición expresa de acuerdos extrajudiciales en este tipo de casos.

Las consecuencias del \#MeToo también han llegado a Europa, provocando que países como Suecia hayan dado un vuelco a su ordenamiento penal con respecto a la violación, la cual ya no hace falta que sea fruto de actos violentos o intimidantes, a partir de ahora está prohibido tener relaciones sexuales con alguien que no haya dicho explícitamente que sí o que demuestre activamente que desea participar (Sen, 2018).

El consentimiento frente a la resistencia es el pilar de la teoría feminista y se ha convertido en piedra angular del \#Yotambién en España, un movimiento que ha estado abanderado por la política Teresa Rodríguez, la actriz Clara Lago, la policía Luisa Velasco y las periodistas Ana Alfageme y Alejandra Agudo, quienes en 2017 rompieron su silencio y sacaron a la luz los abusos sexuales que habían sufrido.

Según la directora de la Agencia de Comunicación y Género, Isabel Mastrodoménico:

Hablar es romper con el estereotipo machista que culpabiliza y responsabiliza a la víctima de una situación que ella no ha creado. La sociedad nos educa a nosotras a cuidarnos para no ser violadas o agredidas, pero no educa a los hombres a que se nos respete. La carga de la culpa cae sobre nosotras y esto dificulta que las mujeres puedan relatar lo sucedido no solo por el peso brutal de lo vivido sino por contarlo y enfrentarse a todo tipo de juicios de terceros por contarlo (Coronado, 2017).

La apropiación de la tecnología digital ha logrado visibilizar las potencialidades del activismo feminista español para comunicar e interpelar a un público masivo. En nuestro país, el movimiento \#MeToo ha calado con especial fuerza debido al 
controvertido caso de La Manada, que ha puesto en el punto de mira un problema generalizado y poco conocido como son las violaciones y agresiones sexuales que se cometen en España durante las fiestas populares y que, sólo en el $20 \%$ de los casos, se denuncian.

Los asaltos sexuales múltiples se han disparado en los dos últimos años. Según cifras de Geoviolenciasexual (2020), durante 2019 se registraron en España 86 agresiones (Ver Imagen 1), que sumadas a las de los dos años anteriores alcanzan los 164 en los últimos tres años. Sin embargo, podría haber muchos casos no registrados, ya que no hay cifras oficiales y el portal web ha realizado su estudio en base a artículos y noticias periodísticas que recogen violaciones o agresiones sexuales públicas.

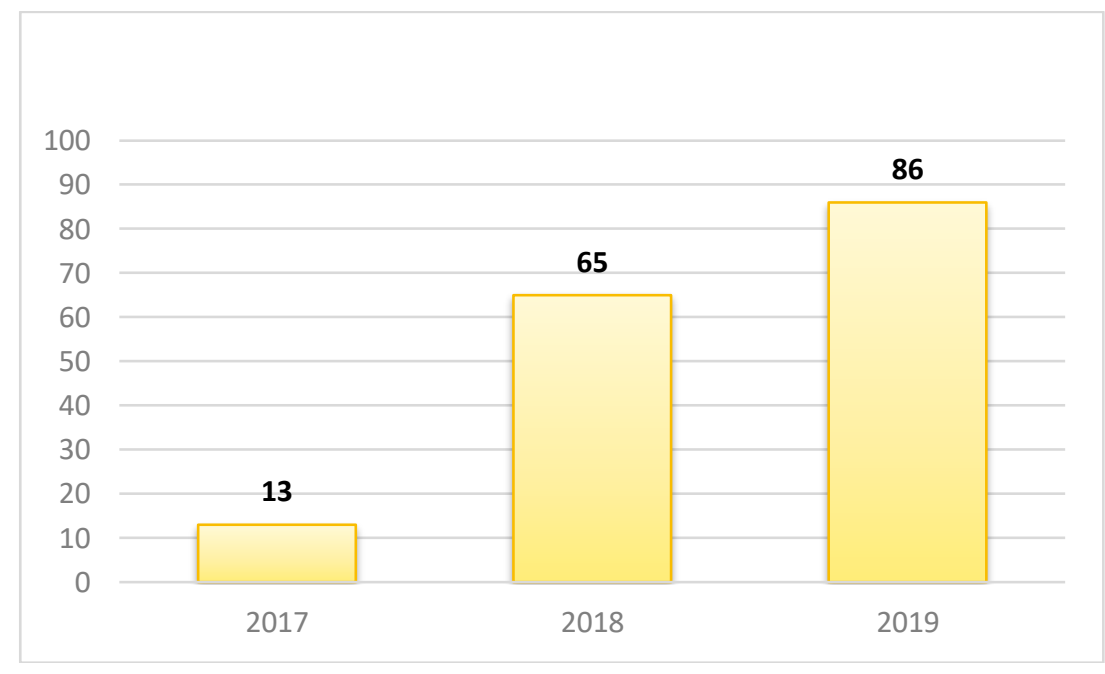

Imagen 1. Agresiones sexuales en España

Fuente: Geoviolenciasexual.com

En este sentido, la Federación de Centros de Asistencia a Víctimas de Agresiones Sexuales (CAVAS), cree que "solo una de cada seis violaciones se convierte en denuncia en España, por lo que la cifra del informe no representa ni se acerca a todos los casos perpetrados y denunciados" (Reguero, 2018).

Este aumento coincide, además, con el de los delitos contra la libertad sexual, que según el Balance de Criminalidad del Ministerio de Interior (2019), aumentaron un $11,3 \%$ durante el pasado año. Las agresiones sexuales con penetración crecieron un $10,5 \%$, mientras que el resto lo hicieron un $11,4 \%$.

Las cifras expuestas ponen de manifiesto el control social y limitación de movimiento de las mujeres en España por culpa del machismo y que encuentran su origen, según Graciela Atencio, coordinadora del informe de Geoviolencia Sexual (2020); en la pornografía hegemónica, es decir, la educación sexual a través de la pornografía de Internet. 
Según Reguero (2018), las violaciones grupales encuentran su origen en la figura del gangbang, en la que grupos de tres o más hombres tienen sexo con una sola mujer, lo cual contribuye a fortalecer el imaginario masculino en el que el cuerpo de las mujeres es un territorio a conquistar.

Dentro de este contexto, el caso de La Manada ha cobrado especial relevancia porque:

Concentra todas las paradojas de un sistema jurídico que revela su lado más patriarcal: el victimario es tratado con una infinidad de presunciones mientras la víctima no solo no suele obtener justicia, sino que por lo general termina ella misma virtualmente condenada, no por un tribunal, sino por un jurado popular implacable, dispuesto a negar la violencia contra ella y a endilgarle un arsenal de estigmas y discriminaciones (Wiener, 2018).

El juicio a La Manada pone el foco en si hubo o no consentimiento por parte de la víctima, lo que ha generado un movimiento de apoyo sin precedentes a la agredida en redes sociales a través de la etiqueta \#Yositecreo, pero también en la calle, donde ha habido una respuesta masiva y contundente de la sociedad en ciudades como Barcelona, Madrid, Zaragoza, Sevilla, Granada y Huelva, donde miles de personas no han dudado en denunciar la actitud machista de la justicia y de los medios de comunicación en torno a este caso.

Las distintas convocatorias lograron superar todas las expectativas reuniendo a mujeres de todas las edades para reivindicar la inclusión de las agresiones sexuales en la Ley de Violencia de Género, para que los juicios se vean en tribunales especializados y para criticar el polémico informe que un detective privado elaboró sobre la actividad en redes sociales de la víctima posterior a la denuncia.

El momento álgido de este proceso se vive el 26 abril de 2018 cuando la justicia condena a los cinco miembros de "La Manada" a una pena de 9 años por un delito de abuso sexual continuado y no por violación, incluso con un voto particular partidario de la absolución. El fallo de la sentencia provoca una oleada de indignación en la sociedad española, y para dejar constancia de la misma se convocan decenas de concentraciones en distintos puntos de España bajo el lema "La manada somos nosotras" (Ver Imagen 2). 


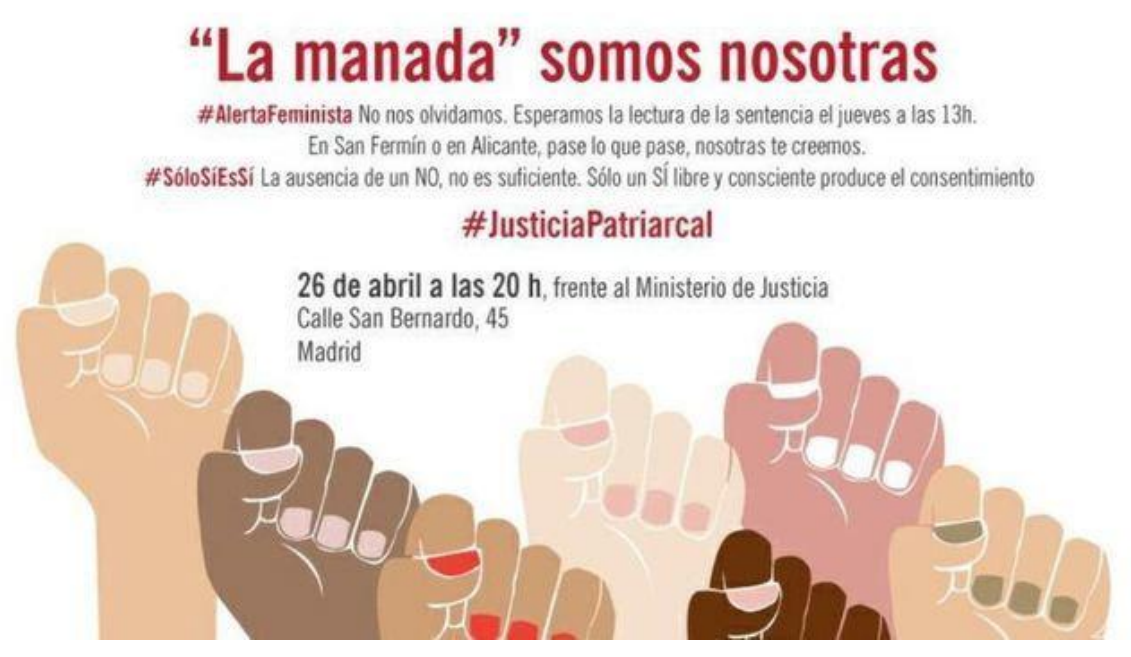

Imagen 2. Convocatoria de manifestación "la manada" somos nosotras

Fuente: Elboletin.com

La polémica sentencia pone de manifiesto la capacidad de Internet para "facilitar los procesos de comunicación, interacción y organización de las luchas sociales, eliminando barreras espacio-temporales y facilitando conquistas justas y necesarias" (Fernández Rincón, 2019, p.72). De inmediato, los colectivos feministas rescataron el \#Yositecreo para repudiar, esta vez, la agresión machista de la resolución de la justicia española y la constante lucha de las mujeres en todo el mundo contra la violencia de género.

El hashtag tuvo tal alcance social, que a él se sumaron, incluso, las monjas Carmelitas Descalzas de Hondarribia (Guipúzcoa), cuyo sentido mensaje generó más de 1.300 comentarios, 14.000 reacciones y fue compartido más de 15.000 veces (Ver Imagen 3).

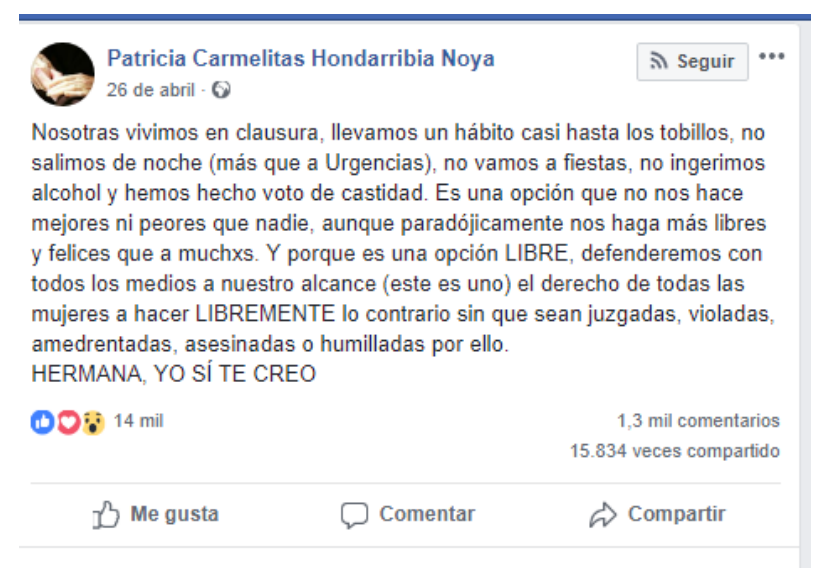

Imagen 3. Post en Facebook de las Carmelitas Descalzas de Hondarribia Fuente: Facebook

Con cerca de un millón y medio de impactos potenciales, \#Yositecreo logró "condensar simbólicamente la confianza en la joven y el hartazgo por la 
culpabilización de las mujeres que sufren violencias sexuales" (Núñez-Puente y Fernández-Romero, 2019, p. 389). De igual forma, pone el foco informativo en que la jurisprudencia española está obsoleta, ya que el concepto de "consentimiento" está atado a cuestiones físicas, como la ausencia o presencia de resistencia o a la carencia o existencia de dolor en el acto sexual.

A través de las redes sociales, las asociaciones feministas denunciaron la sentencia valorándola como especialmente negativa y junto a celebrities nacionales e internacionales tomaron el ciberespacio para reivindicar su descontento y reclamar a los jueces formación en perspectiva de género, tal y como se recoge en el Pacto de Estado contra la violencia de género. Es el caso de la actriz Jessica Chastain, quien publicaba en su perfil de Twitter: "Bajo la ley española, 'el delito menor de abuso sexual difiere de la violación en que no implica violencia o intimidación'. ¿No hay intimidación? Cinco extraños llevando a una mujer intoxicada a un lugar desconocido es increíblemente aterrador e intimidante. ¿Cuántas mujeres mueren cada año?".

Etiquetas como: \#EstaEsNuestraManada, \#Niunamenos, \#JusticiaPatriarcal, \#NoesNo, \#Lamanadasomosnosotras y \#Yositecreo fueron trending topic en Twitter durante toda la jornada del 26 de abril (Ver Imagen 4) y el nexo de unión usado por multitud de caras conocidas de ámbitos tan diversos como los políticos Pedro Sánchez, Pablo Iglesias y Carolina Bescansa, la actriz y directora Leticia Dolera, la presentadora Eva González, la influencer Laura Escanes, el cantante Alejandro Sanz o el periodista Jordi Évole, entre otros muchos, para luchar contra la violencia de género y acabar con las injusticias.

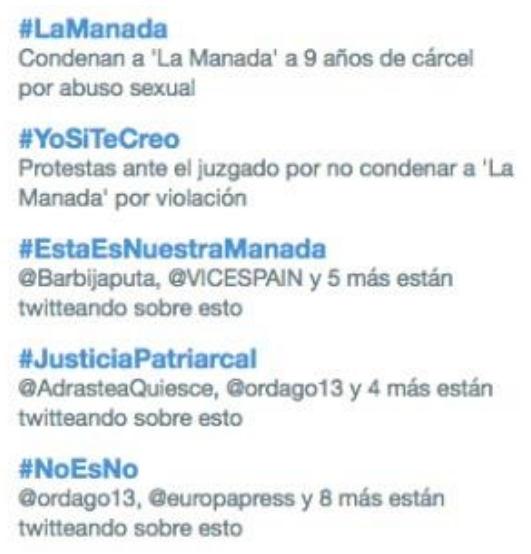

Imagen 4. Trending topic del 26 de abril de 2018.

Fuente: Twitter

La presión social online y offline provocó que al día siguiente el portavoz del Gobierno, Íñigo Méndez de Vigo, anunciara el encargo de un estudio técnico sobre si la tipificación de los delitos contenidos en el código Penal sobre agresiones sexuales era adecuada y que ha derivado en el anteproyecto de ley de garantía integral de la libertad sexual de marzo de 2020 que regula hasta tres tipos de acoso: entre ellos el 
ocasional, no reiterado pero sexista o sexual que se castigará con penas de localización permanente; el 'staljking' o acoso continuado y el acoso sexual (Gil, 2020).

Según la ministra de Igualdad, Irene Montero, "la ley del 'solo sí es sí' es la ley del movimiento feminista" (Martín, 2020), pero, también, es la consigna que resume el nuevo modelo penal que recoge el convenio de Estambul, firmado por 20 estados miembros de la Unión Europea en el año 2011, a la vanguardia de la legislación feminista en términos sexuales, y en el que queda claro que "el consentimiento debe prestarse voluntariamente como manifestación de libre arbitrio de la persona considerado en el contexto de las condiciones circundantes" (Sen, 2018).

\title{
4.2. Manifestación \#8M
}

Influenciada y enmarcada por un contexto internacional que fomenta el crecimiento de una conciencia feminista global, la huelga del 8 de marzo de 2018 situó a España a "la vanguardia del movimiento feminista global" (Ideograma, 2019, p.24) y prueba de ello son las crónicas realizadas por la prensa internacional, que llevó el éxito de la convocatoria a las portadas de todo el mundo.

Así, The Guardian (2018) destacó la alta participación ("Más de 5 millones se unen a la 'huelga feminista' de España, dicen los sindicatos"), Le Monde (2018) resaltó el respaldo de los movimientos sociales y sindicales (Ver Imagen 5) para "parar el mundo", mientras que el diario italiano La Repubblica (2018) precisaba que se trataba de "la manifestación más grande de la lucha feminista".

\section{In Europe \\ INTERNATIONAL EUROPE Européennes 2014 Allemagne Belgique Espagne Grèce Italie Roya}

\section{En Espagne, les femmes font grève pour " arrêter le monde "}

\author{
Malgré des progrès considérables en vingt ans, les femmes espagnoles sont \\ toujours payées près de $15 \%$ de moins que leurs confrères masculins. \\ LE MONDE | 08.03.2018 à 02h51 • Mis à jour le 08.03 2018 à 03h17 | \\ Par Sandrine Morel (Madrid, correspondance)
}

Imagen 5. Noticia publicada por Le Monde

Fuente: lemonde.fr

Por su parte, The Washington Post (2018) señaló la reivindicación de las mujeres "para protestar contra los salarios injustos y la violencia machista con una cacerolada conjunta", al tiempo que el New York Times (2018) publicaba un especial titulado "Día 
internacional de la Mujer 2018: Más allá del \#MeToo, con orgullo, protestas y presión" en el que se destaca el paro laboral y doméstico de las mujeres.

España cambió el 8 de marzo de 2018. 123 manifestaciones, 192 concentraciones y 185 acciones dan idea del seguimiento de una huelga cuyo objetivo era demostrar que sin las mujeres el mundo se para, porque sin ellas ni se produce ni se reproduce. La huelga general, dirigida a la mitad de la población, no sólo estaba enfocada al ámbito laboral, era también una huelga de cuidados, estudiantil y de consumo y se basaba en el precedente histórico del paro producido por el $90 \%$ de las mujeres de Islandia en 1975, quienes paralizaron el país y provocaron un punto de inflexión en la isla nórdica.

El manifiesto de respaldo a la huelga del 8 de marzo fue consensuado en una reunión de 400 mujeres celebrada en enero en Zaragoza. El él se reclamaba el final de las agresiones y la violencia machista, el pago de pensiones justas, una educación pública, laica y feminista, y apelaba a un "feminismo interseccional" (Corral, 2018), aquel que va desde el trabajo asalariado hasta el ejercicio de los derechos de las mujeres, pasando por la formación o la participación ciudadana.

La denominada "tercera ola del feminismo" arrancó en los años 90, cuando las pioneras en la lucha por la igualdad ya habían conseguido infinidad de derechos: el sufragio, la entrada en el mercado de trabajo, el acceso a profesiones tradicionalmente masculinas... Sin embargo, continúa Heredia (2018), “faltaba la denuncia, quedaba dar voz a las mujeres maltratadas", $\mathrm{y}$, sobre todo, quedaba pendiente visibilizar conceptos como brecha salarial, techo de cristal, acoso sexual o trabas a la conciliación.

Parte de esta revolución llega de la mano del movimiento \#MeToo, considerado como el cambio social más rápido de las últimas décadas. A raíz de este fenómeno, la revolución feminista organizada a través de las redes sociales comienza a gestar una huelga y unas movilizaciones que en España sólo pueden ser comparables a las de rechazo contra la banda terrorista ETA y las del movimiento 15M.

El movimiento 8M en España cuenta con una plataforma unificada que centraliza información, recursos materiales y facilita la labor de comunicación y difusión de los actos y movilizaciones programadas. Además, en los dos últimos años "se ha enriquecido visiblemente gracias a la co-creación de contenidos y recursos" (Fernández Rincón, 2019, p.71). Sin embargo, el éxito de la concentración se debe a una combinación de interacción directa e indirecta.

La familiaridad que las jóvenes tienen con las redes sociales las convierte en un instrumento idóneo para involucrarlas en la participación social, sobre todo si se trata de un tema que exige una respuesta solidaria y que les atañe de cerca. En ello ha jugado un papel primordial Facebook. La red social ha permitido generar una comunidad cohesionada en la que el debate feminista es activo y endogámico, lo que permite hacer visible muchas demandas y, lo más importante, facilita la capacidad de movilización colectiva. 
Sin embargo, en la huelga del 8M su principal arma fue Twitter. A dos días de la convocatoria feminista, miles de tuits convirtieron el hashtag \#EsMachismoCuando (Ver Imagen 6) en el principal tema de conversación a nivel nacional. La red social del pajarito se llenó del testimonio de mujeres denunciando los comportamientos patriarcales que tienen que soportar diariamente, pero también de usuarios que se manifestaron en contra "alimentando la conversación, e incluso los trolls que, recurriendo al insulto y al desprecio, han demostrado lo necesario que es este debate" (Público, 2018).

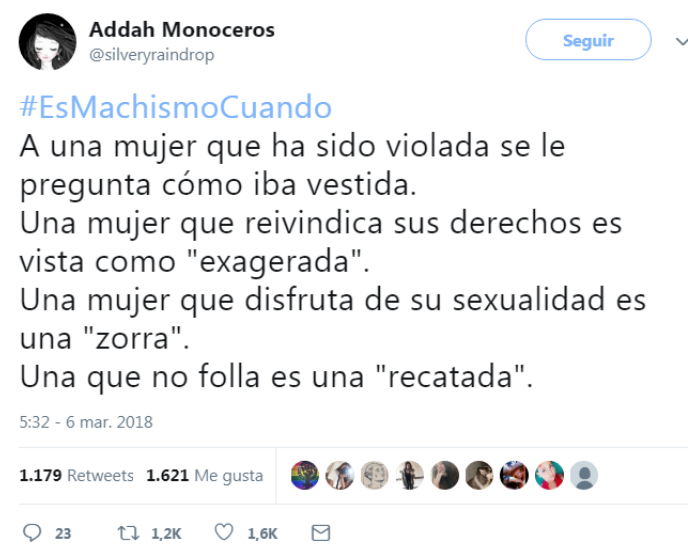

Imagen 6. Tuit publicado bajo el hashtag \#EsMachismoCuando Fuente: Twitter

El 8M la huelga feminista fue compartida y reivindicada a través de 38 hashtags que sintetizaron consignas fáciles y asumibles por el conjunto de la sociedad, como es el caso de: \#Estamoshartasde, \#DiaDeLaMujer, \#8deMarzoHuelgaFeminista y \#El8demarzoyoparo. Todos ellos fueron tendencia. También tuvo gran trascendencia el manifiesto "las periodistas paramos", firmado por casi 4.000 profesionales, sobre todo por la visibilidad que le otorgaron los medios de comunicación y la parada de programas de máxima audiencia.

En total, ese día se enviaron casi dos millones de mensajes, de los cuales el $85 \%$ fueron retuits (Ideograma, 2018), y que hicieron que el Día de la Mujer fuera trending topic durante toda la jornada. El valor de estos mensajes reside en que las mujeres pudieron compartir sus vivencias personales, lo cual permitió crear una especie de conciencia de experiencias compartidas.

Las redes sociales han tenido un papel indispensable en el empoderamiento femenino y, en este sentido, el especialista en Historia que Moderna, Franco Ruiz, afirma que:

Es tan importante este instante como lo fue el de las sufragistas británicas, que se daban cuenta de que estaban cambiando la historia. Hemos despertado. Esto es mundial. El paso es grande. Es un hito. Porque el sistema patriarcal no se 
esperaba este nuevo levantamiento de la mujer que quiere la igualdad absoluta (Yankee, 2018).

En esta misma línea se pronuncian Sánchez-Duarte y Fernández Romero (2017, p.900) para quienes la red “potencia la sensación de comunidad y la democratización de la divulgación y visibilidad de sujetos feministas más diversos". Gracias a las redes sociales, afirma Beatriz Ranea, "se han llegado a contextos antes inalcanzables" y ello se ve claramente en el hecho de que "sale una sentencia injusta y, esa misma tarde, se convoca una concentración" (Llorente, 2019).

Las redes permiten promover y consolidar modelos de conducta que rápidamente son imitados, es por ello que permiten establecer lazos colaborativos y generar espacios de debate público. En el caso de los colectivos feministas han encontrado en Facebook su principal plataforma de debate, en Twitter un medio de hacer lobby y en Instagram una plataforma con la que crear, ampliar y fidelizar su comunidad (Cordero, 2018).

Por su parte, Whatsapp y Telegram se han convertido en un medio idóneo para la propagación de carteles y llamamientos a la acción. Su principal cometido es servir de repositorio digital de imágenes, noticias y mensajes, pero también se ha erigido en un importante foro en el que debatir y visibilizar problemáticas como la brecha salarial que acompaña a las mujeres a lo largo de toda su vida laboral y que, concretamente, es del 22\% respecto al salario medio de los hombres (INE, 2019).

En España aún no se ha logrado la paridad, pero sí se han alzado numerosas voces para denunciar este problema, de hecho, la edición 2018 de los Premios Goya (3 de febrero) se llenó de abanicos rojos con el hasthag \#Masmujeres que reclamaban una mayor presencia femenina en el cine español, un sector en el que, según datos de la Asociación de Mujeres Cineastas y de Medios Audiovisuales, sólo hay un $7 \%$ de mujeres directoras y un $2 \%$ de directoras de fotografía.

La pluralidad de actos reivindicativos vividos durante 2018 ha terminado por calar en la clase política española, instándola a trabajar para paliar la desigualdad entre hombres y mujeres. Así, con fecha 7 de marzo de 2019 el BOE publicaba el Real Decreto-ley 6/2019, de 1 de marzo, de medidas urgentes para garantía de la igualdad de trato y de oportunidades entre mujeres y hombre en el empleo y la ocupación, que pretende resolver la brecha salarial y afronta todos los problemas de discriminación, entre ellos el reparto equilibrado en los puestos de dirección.

\section{DISCUSIÓN}

2018 quedará como el inicio de la era del empoderamiento de las mujeres. Gracias a las redes sociales, las mujeres han puesto de manifiesto las barreras estructurales de género que limitan sus capacidades tanto a nivel individual como colectivo y han reivindicado, en términos de igualdad, el acceso a los recursos y tomas de decisiones en todos los ámbitos de su vida personal y social. 
Muchos son los logros obtenidos gracias a la presión social ejercida por un grupo que conforma la mitad de la humanidad y que reclama su capacidad para luchar por sus derechos y una igualdad efectiva en el acceso a los recursos básicos. Para ello, los procesos comunicativos en la red se han convertido en vías de difusión de información con un gran potencial de interacción real, hasta el punto de impulsar transformaciones sociales y lograr objetivos políticos concretos.

La alianza estratégica de las redes online y offline ha potenciado la lucha contra la violencia hacia las mujeres generando un ciberactivismo interactivo y proactivo que ha logrado incluso trascender al mundo de la empresa privada y de la política, al tiempo que ha permitido poner en cuestionamiento decisiones judiciales y provocar un paro nacional en respuesta a la violencia física, psicológica, simbólica, económica y patrimonial que experimenta el género femenino.

Movimientos como el \#Yositecreo o el \#8M han servido para poner fin a décadas de apatía participativa en España. Las mujeres han decidido alzar la voz y decir basta gracias al empuje de un sector de féminas muy jóvenes que se han convertido en activistas muy organizadas gracias a las redes sociales y herramientas de mensajería instantánea, las cuales han jugado un papel importante en la unión de mujeres con problemáticas comunes, pero también dando voz a esos problemas cotidianos y diarios a los que se enfrentan las mujeres de todas las esferas.

Mujeres que se han educado en la firme creencia de una igualdad pero que a la hora de la verdad se han encontrado con que la igualdad real no existe, que las mujeres tienen un techo de cristal difícil de romper, que a igualdad de trabajo y horas cobran menos que sus compañeros, que tienen que seguir luchando por una conciliación familiar y laboral, que padecen la carga emocional de sus casas y que encima tienen que aguantar que las acosen y vivir con miedo a que los hombres pongan fin a sus libertades.

Por delante aún quedan muchos retos, 2018 sólo ha sido una parada más en la lucha por la igualdad que las féminas vienen reclamando desde el siglo XIX y que, de momento, continúa siendo el desafío principal en torno al que se articula la Agenda 2030 para el Desarrollo Sostenible, ya según datos del Banco Mundial (2017), a nivel mundial, las mujeres representan el $28,8 \%$ de quienes se dedican a la investigación, mientras que sólo 1 de cada 5 países ha logrado la paridad de género en este sentido, en 49 países aún se carece de legislación sobre violencia doméstica, 45 países no aborda de manera específica el acoso sexual y en 37 países aún se exime legalmente a los violadores si están casados con la víctima o se casan posteriormente con ellas.

\section{REFERENCIAS}

Alonso, M. (2014). Redes sociales y ciberactivismo: el poder de las plataformas antidesahucio. En: AA. VV., Derechos humanos emergentes y periodismo (85-106.) 
Sevilla: Equipo de Investigación de Análisis y Técnica de la Información, Universidad de Sevilla

Alonso, M. (2015). Podemos: el ciberactivismo ciudadano llega a la política europea. Dígitos, 1, 91-110.

Banco Mundial (2017). Women, Business and the law. http://wbl.worldbank.org

Bekmezian, H. (2017). Comment l'affaire du hashtag \#balancetonporc est née. https:// www.lemonde.fr/idees/article/2017/12/30/comment-l-affaire-duhashtag-balancetonporc-est-nee_5235955_3232.html

Burgos Pino, E. (2017). El Ciberactivismo: perspectivas conceptuales y debates sobre la movilización social y política, en Revista Contribuciones a las Ciencias Sociales. http://www.eumed.net/rev/cccss/2017/02/ciberactivismo.html

Caldevilla D. (2009). Democracia 2.0: La política se introduce en las redes sociales. Pensar la Publicidad, III(2), 31-48.

Cordero, A. (2017). Cómo el feminismo ha sabido entender las redes sociales. https://agencia.best/blog/feminismo-redes-sociales

Coronado, N. (2017). Las \#MeToo españolas: estas cinco mujeres conocidas denuncian acoso sexual. $\quad$ https://www.elespanol.com/reportajes/20171231/metoo-espanolasmujeres-conocidas-denuncian-acoso-sexual/273223315_0.html

Corral, M. (2018). Huelga feminista el 8 de marzo: ni trabajo, ni consumo, ni tareas domésticas. https://www.elespanol.com/social/20180116/huelga-feministamarzo-trabajo-consumo-tareas-domesticas/277473320_0.html

Danitz, T. y Strobel, Warren P. (1999). The Internet's impact on activism: The case of Burma. Studies in Conflict and Terrorism, 22, 257- 69.

De Ugarte, D. (2007). El Poder de las redes. Barcelona: El Cobre

Della Porta, D. y Diani, M. (2006). Social movements. An introducction. London: Blackwell Publishing.

Diario de Sevilla. (2018). Las etiquetas de Twitter celebran su día. https://www.diariodesevilla.es/tecnologia/etiquetas-Twitter-herramientaconectar_0_1275472946.html

Escobar, N. (2016). El papel de las redes sociales en la lucha por la igualdad de género. https://hipertextual.com/2016/01/redes-sociales-e-igualdad-de-genero 
Ezy Insights. (2017). \#MeToo, lo más viral de 2017. https://ezyinsights.com/metooviral-event-2017-2/

Feliciano, A. y Mallavibarrena, M. (2013). ¡Socorro, quiero ser digital! Madrid: LID.

Fernández, D. y Rubira, R. (2012). Praxis feminista española en Internet: Activismo político online contra la violencia de género. En: AA.VV. (Eds.). Libro de Actas I Congreso Internacional de Comunicación y Género. Universidad de Sevilla.

Fernández Rincón, A. R. (2019). Activismo y co-creación: la comunicación digital de la huelga feminista del 8M. Dígitos, 5, 56-74.

FRA (2014). Violencia de género contra las mujeres: una encuesta a escala de la UE. https:/ / fra.europa.eu/sites/default/files/fra-2014-vaw-survey-at-a-glanceoct14_es.pdf

Gago, R. (2019). Ciberfeminismo en España: discurso teórico y prácticas digitales. Alicante: Coleción Lilith.

Gajjala, R. y Ju Oh, Y. (2012). Cyberfeminism 2.0. London: Digital Formations.

Geoviolenciasexual.com (2020). Agresiones sexuales multiples en España 2016-2020. https://geoviolenciasexual.com/

Gil, I. (2020). Menos pena para agresión y violación y un delito de acoso ocasional: la ley Montero. $\quad$ https://www.elconfidencial.com/espana/2020-03-03/ley-libertadsexual-si-es-si-violacion-abuso_2479251/

Giugni, M. (2004). Social Protest and Policy Change. Lanham, MD: Rowman and Littlefield.

Guirao, J. A., Olmedo, A., y Ferrer, E. (2008). El artículo de revisión. Revista Iberoamericana de Enfermería Comunitaria, (1) 1, 1-25. $\underline{\text { http://www.uv.es/joguigo/valencia/Recerca_files/el_articulo_de_revision.pdf }}$

Haraway, D. (1991). Simians, cyborgs and women: The reinvention of nature. New York: Routledge.

Kember, S. (2003). Cyberfeminism and Artificial Life. London: Routledge.

Hollywood Reporter (2018). Studios Gamble on James Franco, Casey Affleck Projects Post\#MeToo Claims. https://www.hollywoodreporter.com/news/studios-gamblejames-franco-casey-affleck-projects-metoo-claims-1134941

Ideograma (2018). La comunicación del movimiento feminista en el Estado español. https://www.ideograma.org/wp- 
content/uploads/2019/03/COMUNICACION_MOVIMIENTO_FEMINISTA_ID G.pdf

INE (2019). Brecha digital género. http://www.ine.es/ss/Satellite?L=es_ES\&c=INESeccion_C\&cid=1259925530071\& $\mathrm{p}=1254735110672 \&$ pagename $=$ ProductosYServicios $\% 2 F P Y S L a y o u t \&$ param $3=1259$ $\underline{924822888}$

La Repubblica (2018). Spagna: milioni di persone in strada per la più grande manifestazione della storia a favore della lotta feminista. https:/ /it.globalvoices.org/2018/03/spagnamilioni-di-persone-in-strada-per-la-piu-grande-manifestazione-della-storia-afavore-della-lotta-femminista/

Le Monde (2018) Espagne, les femmes font grève pour «arrêter le monde». https://www.lemonde.fr/europe/article/2018/03/08/en-espagne-les-femmesfont-greve-pour-arreter-le-monde_5267305_3214.html

Llanos, I. (2017). \#MeToo, un movimiento de hace 10 años que se reactiva con el 'caso Weinstein'. $\quad$ https://www.elperiodico.com/es/extra/20171023/metoomovimiento-contra-abusos-sexuales-6372524

Llorente, S. (2019). Beatriz Ranea. "El ciberactivismo ha sido fundamental en el resurgir de la cuarta ola feminista". https://valenciaplaza.com/beatriz-ranea-el-ciberactivismoha-sido-fundamental-en-el-resurgir-de-la-cuarta-ola-feminista

Martín, J. (2020). La ley del 'solo sí es sí: penas de hasta 15 años de cárcel para el delito de violación y el consentimiento como clave. https://www.rtve.es/noticias/20200303/ley-del-solo-si-si-penas-1-4-anosagresion-sin-consentimiento/2005130.shtml

Ministerio del Interior (2019). Balance trimestral de la Criminalidad. http://www.interior.gob.es/documents/10180/8736571/01_Informe+Balance+Cr iminalidad+-+Primer+trimestre+2018.pdf/f8a31d99-7275-436a-a66a-22e88832ae4d

Núñez Puente, S., Rubira. R., y Fernández, D. (2013). La construcción del sujeto víctima de violencia de género en Youtube como acto performativo: estudio del activismo online desde el análisis multimodal. Cuadernos Kóre. Revista de historia y pensamiento de género, 22, 179-199.

Núñez Puente, S., Fernández, D. y Peña, P. (2016). Ciberactivismo contra la violencia de género: Fetichismo tecnológico e interactividad. Feminismo, 27, 177-195.

Núñez Puente, S., Vázquez-Cupeiro, S. y Fernández-Romero, D. (2016). Ciberfeminismo contra la violencia de género: análisis del activismo online-offline y de la representación discursiva de la víctima. Estudios sobre el mensaje periodístico, 22(2), 861-877. 
Núñez Puente, S. y Fernández-Romero, D. (2019). Posverdad y victimización en Twitter ante el caso de La Manada: propuesta de un marco analítico a partir del testimonio ético, en Investigaciones Feministas, 10(2), 385-398.

OCDE (2018). Toolkit for Mainstreaming anda Implementing Gender Equality. http://www.oecd.org/gender/governance/toolkit

Público (2018). Las tuiteras se suman al hashtag de 'Público' \#EsMachismoCuando y denuncian los comportamientos patriarcales que sufren a diario. https://www.publico.es/tremending/2018/03/06/huelga-feminista-del-8-demarzo-las-tuiteras-se-suman-al-hashtag-de-publico-esmachismocuando-ydenuncian-los-comportamientos-patriarcales-que-sufren-a-diario

Ramírez Morales, M. R. (2019). Ciberactivismo mestrual: feminismo en las redes sociales. PAAKT: revista de tecnología y sociedad, 19(17). http:/ / www.scielo.org.mx/scielo.php?script=sci_arttext\&pid=S200736072019000200009\#B28

Reguero, P. (2018). En 2018 ha habido tantas agresiones sexuales en manada como en todo $2016 . \quad$ https://www.elsaltodiario.com/violencia-sexual/en-2018-se-han$\underline{\text { registrado-tantas-agresiones-sexuales-multiples-como-en-todo-el-2016 }}$

Reguillo, R. (2017). Paisajes insurrectos. Madrid: NED Ediciones.

Reverter, S. (2009). El ruido de la teoría feminista, en Cuadernos Kóre, 1(1), 53-68.

Sánchez-Duarte, J. M. y Fernández-Romero, D. (2017). Subactivismo feminista y repertorios de acción colectiva digitales: prácticas ciberfeministas en Twitter, en El profesional de la información, 26(5), 894-902.

Scott, A. y Street, J. (2000). From media politics to e-protest. The use of popular culture and new media in parties and social movements. Information, Communication $\mathcal{E}$ Society, 3(2), 215-240.

Sen, C. (2018). Suecia aprueba la ley en la que el sexo sin consentimiento será violación. https://www.lavanguardia.com/internacional/20180525/443816457117/sueciaaprueba-ley-sexo-sin-consentimiento-violacion.html

Sierra-Caballero, F. (2018). Ciberactivismo y movimientos sociales. El espacio público oposicional en la tecnopolítica contemporánea (73.a ed.). Revista Latina de Comunicación Social. https://doi.org/10.4185/RLCS-2018-1292 http://www.revistalatinacs.org/073paper/1292/51es.html

Tascón, M. y Quintana, Y. (2012). Ciberactivismo. Las nuevas revoluciones de las multitudes conectadas. Madrid: La Catarata. 
The Guardian (2018). More than 5m join Spain's 'feminist strike', unions say. https://www.theguardian.com/world/2018/mar/08/spanish-women-give-upwork-for-a-day-in-first-feminist-strike

The New York Times (2018). International Women's Day 2018: Beyond \#MeToo, With Pride, Protests and Pressure. https://www.nytimes.com/2018/03/08/world/international-womens-day$\underline{2018 . h t m l}$

The Washington Post (2018). Spain kicks off International Women's Day with a strike. https://www.washingtonpost.com/gdprconsent/?next_url=https $\% 3 a \% 2 f \% 2$ fwww.washingtonpost.com $\% 2$ fvideo $\% 2$ fworl d\%2fspain-kicks-off-international-womens-day-with-a-strike_video.html

Tilly, C. (2009). Los movimientos sociales. 1768-1999. Desde sus orígenes a Facebook. Madrid: Libros de Historia.

Van Dijk, T. (1980). Estructuras y funciones del discurso. México: Siglo XXI editores.

Wiener, G. (2018). Por un mundo sin manadas. https://www.nytimes.com/es/2018/02/23/opinion-wiener-manada-espanaabuso-sexual

Yankee, R. (2018). Del Movimiento sufragista al movimiento \#MeToo: así crece el feminismo. http://www.elmundo.es/papel/historias/2018/03/07/5aa01d5146163f713d8b46 $\underline{68 . h t m l}$

\section{AUTORA}

\section{Marián Alonso-González}

Marián Alonso González es Doctora en Comunicación por la Universidad de Sevilla (2008) con una Tesis Doctoral que versa sobre el cambio tecnológico de $A B C$ de Sevilla. Miembro de la Asamblea de Mujeres Periodistas de Sevilla y del Censo de Expertas, compagina su labor profesional como Técnico de Comunicación en Adif con su labor docente como profesora asociada en la Facultad de Comunicación de Sevilla, donde imparte clases de nuevas tecnologías y redacción. Especializada en redes sociales, ha orientado su investigación a campos relacionados con la Comunicación 2.0, el Periodismo 3.0, las audiencias sociales y los nuevos lenguajes multimedia e interactivos.

malonsog@us.es

Orcid ID: https:/ / orcid.org/0000-0003-2676-0449

Google Scholar: $\underline{\text { https://scholar.google.com/citations? user=pTW9yp0AAAAJ\&hl }}$

ResearchGate: https://www.researchgate.net/profile/Alonso_Marian

Scopus ID: $\underline{57000544900}$ 
Alonso-González, M.

Activismo social femenino en la esfera pública digital

Academia.edu: https://us.academia.edu/Mari\%C3\%A1nAlonso 